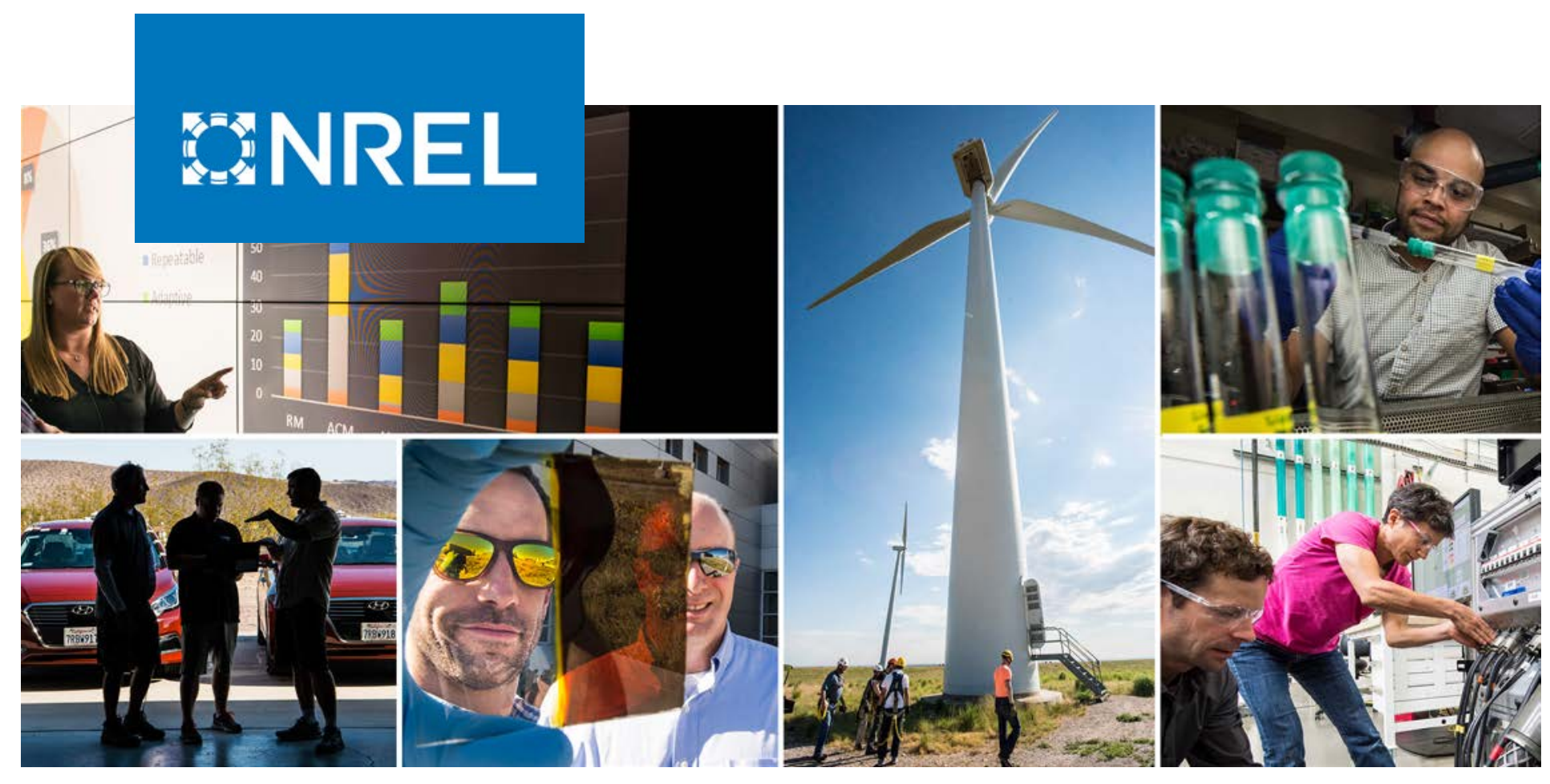

\title{
Validation of Photovoltaic Modeling Tool HelioScope Against Measured Data
}

Darice L. Guittet and Janine M. Freeman

National Renewable Energy Laboratory

NREL is a national laboratory of the U.S. Department of Energy

Office of Energy Efficiency \& Renewable Energy

Operated by the Alliance for Sustainable Energy, LLC

This report is available at no cost from the National Renewable Energy Laboratory (NREL) at www.nrel.gov/publications.

\section{Technical Report}

NREL/TP-6A20-72155

November 2018 


\section{GHREL}

\section{Validation of Photovoltaic Modeling}

Tool HelioScope Against Measured Data

Darice L. Guittet and Janine M. Freeman

National Renewable Energy Laboratory

\section{Suggested Citation}

Guittet, Darice L., and Janine M. Freeman. 2018. Validation of Photovoltaic Modeling Tool HelioScope Against Measured Data. Golden, CO: National Renewable Energy Laboratory. NREL/TP-6A20-72155. https://www.nrel.gov/docs/fy19osti/72155.pdf.

NREL is a national laboratory of the U.S. Department of Energy Office of Energy Efficiency \& Renewable Energy Operated by the Alliance for Sustainable Energy, LLC

This report is available at no cost from the National Renewable Energy Laboratory (NREL) at www.nrel.gov/publications.

Contract No. DE-AC36-08GO28308
Technical Report NREL/TP-6A20-72155 November 2018

National Renewable Energy Laboratory 15013 Denver West Parkway Golden, CO 80401

303-275-3000 • www.nrel.gov 


\section{NOTICE}

This work was authored by the National Renewable Energy Laboratory, operated by Alliance for Sustainable Energy, LLC, for the U.S. Department of Energy (DOE) under Contract No. DE-AC36-08G028308. Funding provided by U.S. Department of Energy Office of Energy Efficiency and Renewable Energy Solar Energy Technologies Office. The views expressed herein do not necessarily represent the views of the DOE or the U.S. Government.

This report is available at no cost from the National Renewable Energy Laboratory (NREL) at www.nrel.gov/publications.

U.S. Department of Energy (DOE) reports produced after 1991 and a growing number of pre-1991 documents are available free via www.OSTI.gov.

Cover Photos by Dennis Schroeder: (clockwise, left to right) NREL 51934, NREL 45897, NREL 42160, NREL 45891, NREL 48097, NREL 46526.

NREL prints on paper that contains recycled content. 


\section{Table of Contents}

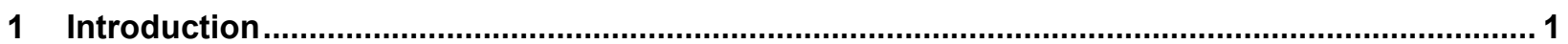

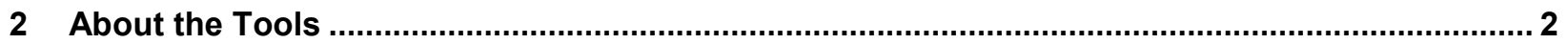

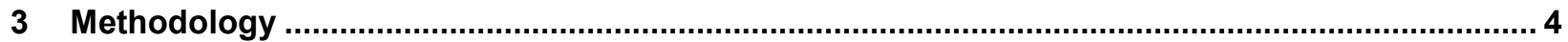

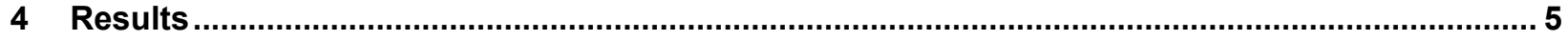

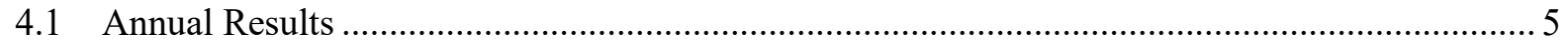

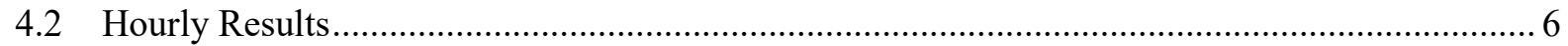

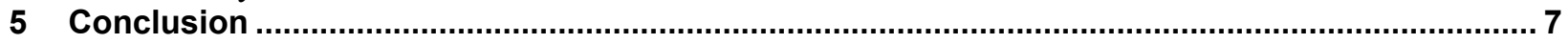

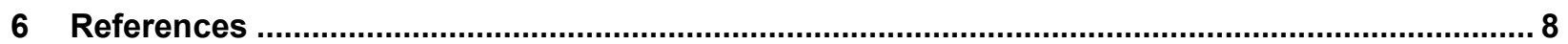




\section{List of Figures}

Figure 1. Annual normalized error for each tool by system ................................................................ 5

Figure 2. Hourly normalized root-mean-square error for each tool by system......................................... 6

\section{List of Tables}

Table 1. Default Internal Models of the Tools................................................................................ 2

Table 2. Default Loss Assumptions of Each Tool ............................................................................ 3

Table 3. PV Systems Modeled in HelioScope ..................................................................................... 4

Table 4. Range of Annual Errors for STF, Forrestal, RSF1, RSF2, Visitor Parking, and FirstSolar2 ......... 5 


\section{Introduction}

HelioScope is a cloud-based solar design software developed by Folsom Labs to model photovoltaic (PV) array systems. Folsom Labs was selected for a Small Business Voucher from the U.S. Department of Energy for the National Renewable Energy Laboratory to validate the performance of HelioScope's simulation engine against measured PV system performance. This study builds on previous validation work by NREL of other PV modeling tools (Freeman et al. 2013, 2014; Freeman and Simon 2015), using the same fixed-tilt systems with available system specifications. HelioScope designs were set up using the same system specifications and concurrent meteorological year data as were used in previous studies. The predicted performance results from the HelioScope simulations were compared to measured data and to performance predictions by other PV modeling tools. 


\section{About the Tools}

HelioScope was validated by comparing results to those of three PV modeling tools: the System Advisor Model (SAM) ${ }^{1}$ 2014.1.14, PVSyst 6.11, and PV*SOL. All simulation results for HelioScope $^{2}$ were calculated using the web-based solar design software between February 2018 and May 2018. Each PV modeling tool differs in which internal submodels are offered and used as default and in which system losses are applied and how they are calculated. While the choice of model and variation of losses will affect the output, each tool is designed with default models and values. The default submodels used by each tool are given in Table 1.

\begin{tabular}{|c|c|c|c|c|}
\hline Value & SAM 2014.1.14 & PVSyst 6.1.1 & PV*SOL & HelioScope \\
\hline Modeling timestep & hourly & hourly & hourly & hourly \\
\hline $\begin{array}{l}\text { Decomposition of global } \\
\text { horizontal irradiance } \\
(\mathrm{GHI})\end{array}$ & $\mathrm{N} / \mathrm{A}$ & Erbs model & Reindl & $\mathrm{N} / \mathrm{A}$ \\
\hline $\begin{array}{l}\text { Transposition to plane- } \\
\text { of-array irradiance }\end{array}$ & Perez & Perez & Hay Davies & Perez \\
\hline Radiation components & $\begin{array}{l}\text { Direct normal } \\
\text { irradiance (DNI) } \\
\text { and diffuse } \\
\text { horizontal } \\
\text { irradiance (DHI) }\end{array}$ & user selection & $\mathrm{GHI}$ & $\mathrm{GHI}$ and $\mathrm{DHI}$ \\
\hline Module model & $\begin{array}{l}\text { California } \\
\text { Energy } \\
\text { Commission } \\
\text { (CEC) single- } \\
\text { diode model }\end{array}$ & $\begin{array}{l}\text { Shockley's } \\
\text { single-diode } \\
\text { model }\end{array}$ & $\begin{array}{l}\text { enhanced } \\
\text { single-diode } \\
\text { model }\end{array}$ & $\begin{array}{l}\text { Shockley's one- } \\
\text { diode model }\end{array}$ \\
\hline Thermal model & NOCT & $\begin{array}{l}\text { thermal balance } \\
\text { equation }\end{array}$ & $\begin{array}{l}\text { thermal balance } \\
\text { equation }\end{array}$ & $\begin{array}{l}\text { Sandia National } \\
\text { Laboratory }\end{array}$ \\
\hline Inverter model & CEC & $\begin{array}{l}\text { grid inverter } \\
\text { model }\end{array}$ & $\begin{array}{l}\text { grid inverter } \\
\text { model }\end{array}$ & CEC \\
\hline Albedo & 0.2 & 0.2 & 0.2 & 0.2 \\
\hline Module cover/IAM loss & $\begin{array}{l}\text { Model- } \\
\text { dependent }\end{array}$ & ASHRAE & ASHRAE & ASHRAE \\
\hline DC-AC ratio & 1.2 & user selection & user selection & user selection \\
\hline
\end{tabular}

Table 1. Default Internal Models of the Tools

${ }^{1}$ See sam.nrel.gov.

${ }^{2}$ See www.helioscope.com. 
To provide consistency between tools, the simulations were created using the default mode for each tool except in the case of which radiation components were used. From prior validation studies, the Total (GHI) and Beam (DNI) weather file inputs were used for SAM, PVSyst, and PV*SOL. However, HelioScope uses Total (GHI) and Diffuse (DHI) as its only irradiance input option. Using different irradiance input options, GHI and DNI versus DNI and DHI, was shown in SAM to result in up to $2.3 \%$ difference in annual energy production error, where the magnitude and direction of the error was inconsistent between systems (Freeman et al. 2013). However, there is no indication as to which pair of irradiance values produces greater accuracy.

The default loss percentages were used because each PV modeling tool has its own set of losses and zero-loss configurations have shown higher root-mean-squared errors (RMSE) by not accounting for losses experienced in real systems. The default losses for each tool are given in Table 2. For those losses that are applied as a fixed assumption for some tools and calculated in a submodel in other tools, the value is reported as calculated when appropriate. Not all the power losses that may occur in a system are listed, as some such as thermal losses due to system configuration are modeled explicitly.

\begin{tabular}{|lllll|}
\hline System Losses & SAMv1 & PVsyst & PV*SOL & HelioScope \\
\hline Deviation from wavelength & N/A & N/A & $1 \%$ & N/A \\
spectrum & $5 \%$ & $0 \%$ & $0 \%$ & $2 \%$ \\
Annual soiling loss & $\mathbf{0 . 9 5}$ & $\mathbf{0 . 9 9}$ & $\mathbf{0 . 9 9}$ & $\mathbf{0 . 9 8}$ \\
\hline Total Environmental Derate & $2 \%$ & $1 \%$ & $2 \%$ & Calculated \\
\hline Mismatch & $0.5 \%$ & $0 \%$ & $0.5 \%$ & N/A \\
Diodes and connections & $2 \%$ & $1.5 \%$ & Calculated & Calculated \\
DC wiring & $0 \%$ & N/A & N/A & N/A \\
Tracking error & $0 \%$ & Module-dependent & $0 \%$ & $2.5 \%$ \\
Nameplate & $\mathbf{0 . 9 6}$ & $\mathbf{0 . 9 5}$ & $\mathbf{0 . 9 7 5}$ & Calculated \\
\hline Total DC Derate & $1 \%$ & $0 \%$ & $N / A$ & $0.50 \%$ \\
\hline AC wiring/cabling losses & $0 \%$ & $0 \%$ & N/A & N/A \\
Step-up/external transformer & $\mathbf{0 . 9 9}$ & $\mathbf{1 . 0 0}$ & $\mathbf{1 . 0 0}$ & $\mathbf{0 . 9 9 5 \%}$ \\
\hline Interconnection/AC Derates & & & & \\
\hline
\end{tabular}

Table 2. Default Loss Assumptions of Each Tool 


\section{Methodology}

Seven PV systems were modeled by NREL in HelioScope; see Freeman et al. (2014) for detailed system specifications. Table 3 shows some of the important features of each system. The Years Modeled column describes which set of concurrently-measured meteorological year weather and performance data (previously quality-controlled to remove sensor errors and system or component downtime) was used for each system (Freeman et al. 2013, 2014). At the time of building the simulations in HelioScope, neither utility scale system (FirstSolar 1 or FirstSolar 2) could be modeled in its entirety as one simulation, so the systems were scaled down to representative $\sim 550-\mathrm{kW}$ blocks. After running the simulations, the performance data were scaled back up to the correct system size.

\begin{tabular}{|l|l|l|l|l|}
\hline System & Size & System Type & Racking Type & Years Modeled \\
\hline Forrestal & Commercial & Fixed tilt & Flush mount & 2009-2010 $(1 \mathrm{yr})$ \\
\hline S\&TF & Commercial & Fixed tilt & Fixed tilt & 2011 \\
\hline RSF 1 & Commercial & Fixed tilt & Flush mount & 2011 \\
\hline RSF 2 & Commercial & Fixed tilt & Flush mount & 2012 \\
\hline Visitor Parking & Commercial & Fixed tilt & Carport & 2012 \\
\hline FirstSolar $1^{\text {a }}$ & Utility & Fixed tilt & Fixed tilt & 2011 \\
\hline FirstSolar 2 & Utility & Fixed tilt & Fixed tilt & 2011 \\
\hline
\end{tabular}

a FirstSolar 1 was not modeled in $\mathrm{PV}^{*} \mathrm{SOL}$ because the number of modules exceeded the Expert version limit.

Table 3. PV Systems Modeled in HelioScope

Within each Racking Type, there are additional parameters such as spacing and height that reflect HelioScope's specialization in system design. Though these parameters were set to be representative of each system to produce as accurate a model as possible, not all of these parameters are inputs common to all the other models. Instead, the appropriate thermal model configuration was chosen in each tool, thus allowing each tool to explicitly calculate the shading and thermal losses due to system design; inputs for the other tools are listed in Freeman et al. (2014).

In HelioScope, the shading loss has contributions from two main factors: (1) "near shading" due to racking type and module spacing, and (2) shading from external structures in the environment. Because these systems are mostly unshaded and because external shading was not considered during the previous validation studies, external structures were not drawn into HelioScope's map-based system design interface, precluding the latter type of shading from being a factor of the total shading loss. As a type of calculated loss, near shading losses are inseparable from the performance simulation in HelioScope and so are included in these results. 


\section{Results}

\subsection{Annual Results}

The annual error of prediction quantifies the overprediction or underprediction of energy production over the entire year, normalized by the measured energy production. It is calculated as (modeled-measured)/measured. Figure 1 shows the annual prediction errors for the four tools. For the FirstSolar1 system, no simulation was performed in PV*SOL as explained above, but the results are shown for the other three tools.

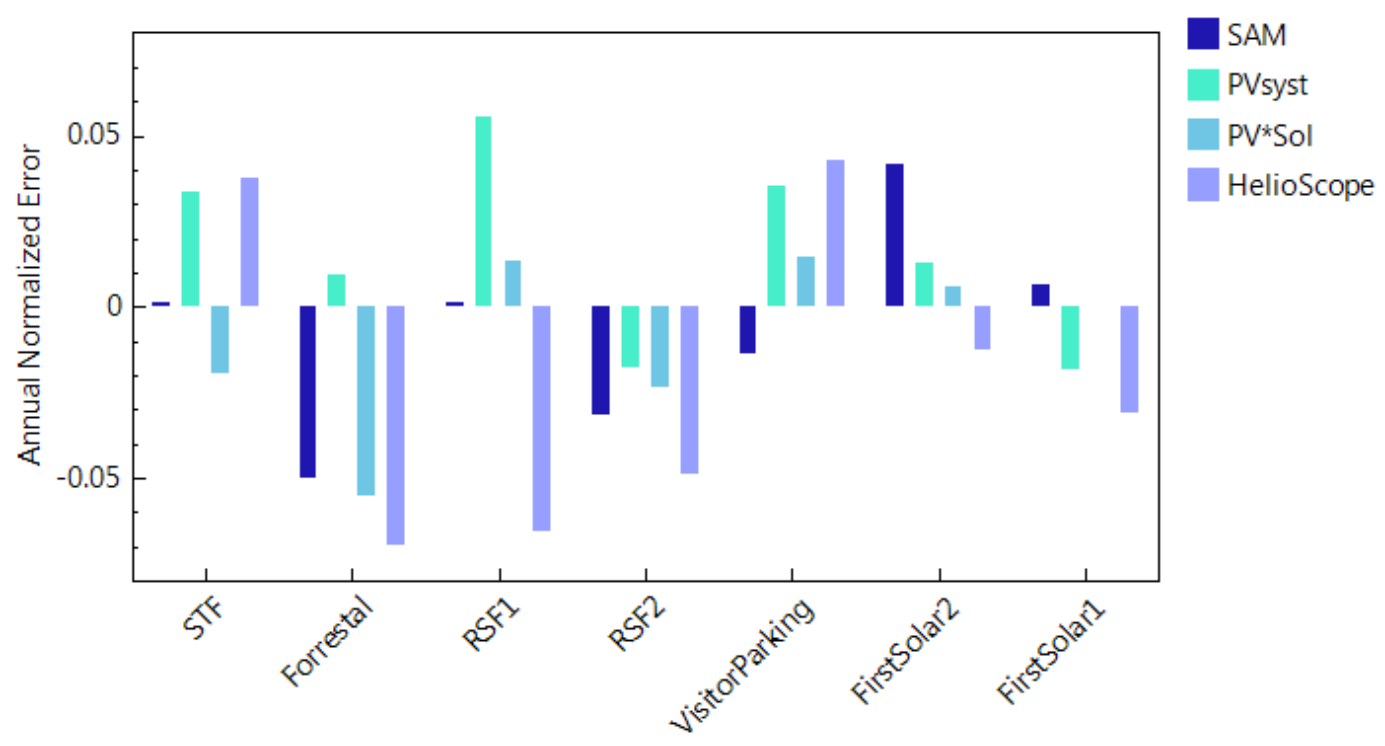

Figure 1. Annual normalized error for each tool by system No data for $\mathrm{PV}{ }^{*} \mathrm{SOL}$ for FirstSolar1.

HelioScope's error range falls between $-7.0 \%$ and $4.3 \%$, which is similar to the range of other tools examined in previous validation studies where the errors are within $\pm 7 \%$. There is no clear pattern as to which tool is more accurate for any type of system, nor is there a pattern to relative overpredicting or underpredicting. The error range for the six systems that were modeled in all four tools (STF, Forrestal, RSF1, RSF2, Visitor Parking, and FirstSolar2) is given in Table 4.

\begin{tabular}{|l|c|}
\hline Tool & Error Range \\
\hline SAM & $-5.0 \%-4.1 \%$ \\
\hline PVsyst & $-1.7 \%-5.5 \%$ \\
\hline PV*Sol & $-5.5 \%-1.4 \%$ \\
\hline HelioScope & $-7.0 \%-4.3 \%$ \\
\hline
\end{tabular}

Table 4. Range of Annual Errors for STF, Forrestal, RSF1, RSF2, Visitor Parking, and FirstSolar2 


\subsection{Hourly Results}

The hourly root-mean-square error (RMSE) is commonly used to evaluate the accuracy on an hourly basis. The normalized RMSE is calculated by taking the square root of the average of squared differences and dividing by the maximum value of the measured data. Figure 2 shows all tools to have an hourly RMSE of $6.6 \%$ or less. HelioScope's hourly RMSE range is between $2.9 \%$ and $6.6 \%$.

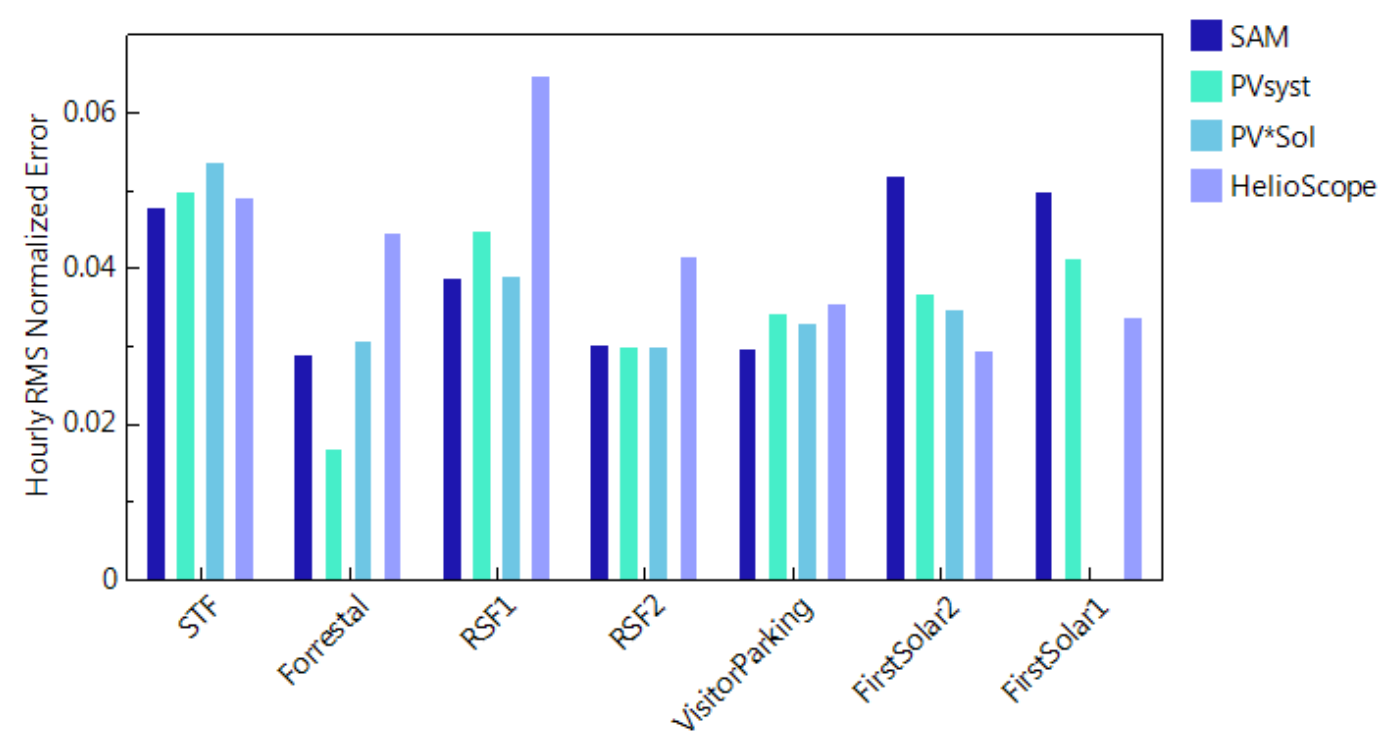

Figure 2. Hourly normalized root-mean-square error for each tool by system No data for $\mathrm{PV}^{*} \mathrm{SOL}$ for FirstSolar1. 


\section{Conclusion}

Seven fixed-tilt systems, of which five were commercial scale and two were utility scale (built as scaled-down units), were modeled in HelioScope in order to validate system performance predictions against measured data and to compare against other PV simulation tools. Unlike the simulations in the other tools, HelioScope's simulations were run using GHI and DHI as input. As with the other simulation tools, external shading was ignored; but unlike the other tools, rowto-row shading effects are an inherent part of HelioScope's calculations and so were factored into these results. HelioScope predictions were comparable with those of other tools, with an annual normalized error range of $-7.0 \%$ to $4.3 \%$ and an hourly normalized RMSE range of $2.9 \%$ to $6.6 \%$. Further validation with a greater variety of system types would provide additional information about the strengths and weaknesses of HelioScope. This study does not comment on the usability of the product. 


\section{References}

Freeman, Janine, Jonathan Whitmore, Leah Kaffine, Nate Blair, and Aron Dobos. 2013. System Advisor Model: Flat Plate Photovoltaic Performance Modeling Validation Report. Golden, CO: National Renewable Energy Laboratory. NREL/TP- 6A20-60204.

https://www.nrel.gov/docs/fy14osti/60204.pdf.

Freeman, Janine, Jonathan Whitmore, Nate Blair, and Aron P. Dobos. 2014. "Validation of Multiple Tools for Flat Plate Photovoltaic Modeling against Measured Fata." 40th IEEE Photovoltaic Specialists Conference.

Freeman, Janine, and Joe Simon. 2015. Analysis of Aurora's Performance Simulation Engine for Three Systems. Golden, CO: National Renewable Energy Laboratory. NREL/TP-7A40-64213 https://www.nrel.gov/docs/fy15osti/64213.pdf. 